\title{
Extracellular Ion Channel Inhibitor Antibodies
}

\author{
Jacqueline Naylor and David J. Beech ${ }^{*}$
}

Institute of Membrane \& Systems Biology, Faculty of Biological Sciences, University of Leeds, Leeds, LS2 9JT, UK

\begin{abstract}
For many ion channels there are no specific pharmacological agents and this impedes searches for the physiological and pathological functions of the ion channels in native systems and restricts opportunity for therapeutic drug development. Antibodies can display high specificity for their target proteins and are routinely engineered to recognise proteins in many experimental procedures and increasingly as therapeutic agents. The unlimited diversity and potential for high specificity make antibodies attractive as biological tools and drugs, although they are not without problems. Along with other investigators we have explored targeting of the E3 extracellular loop (or turret) as an approach for the generation of antibodies with the potential to block certain types of ion channel with isoform specificity. The approach has led to success with nine ion channels and effective use in vitro and in vivo. Here we review current knowledge and experience of channel-blocking antibodies, focusing particularly but not exclusively on E3-targeting.
\end{abstract}

Keywords: Ion channel, transient receptor potential, antibody.

\section{INTRODUCTION}

Ion channels play critical roles in physiology and disease by modulating cellular functions such as electrical excitability, secretion, cell migration, and gene transcription [1]. Chemicals or reagents with the ability to inhibit or increase the flow of ions through such channels are essential for ion channel characterisation, determination of physiological roles, and the production of new therapeutic drugs. To date, many ion channel modulators have been discovered through studies of naturally occurring substances such as toxins from plants and venomous animals, for example conotoxin block of voltage gated $\mathrm{Ca}^{2+}$ channels [2], or through studies of synthetic chemicals leading, for example, to dihydropyridine $\mathrm{Ca}^{2+}$ channel antagonists [3].

Many current drug development programmes are based on screening vast chemical libraries using high throughput systems [4, 5]. Unfortunately, the costs and timecommitments for such screens are high, making early validation of targets by other means a valuable step. Validation may often occur through approaches that suppress or delete channel expression, for example by RNA interference or gene disruption. While these are established methods and may lead to therapeutic agents in their own right, there are limitations conferred by gene networks and associated compensatory effects. A selective and acute method for inhibiting ion channel activity is always a helpful additional approach. There is currently an abundance of chemicals that are known to act as ion channel modulators, but many of these agents are non-selective. Even if selectivity is evident, it is rare that chemicals have the ability to differentiate between channel isoforms within the same family.

\footnotetext{
*Address correspondence to this author at the Institute of Membrane \& Systems Biology, Garstang Building, Faculty of Biological Sciences, University of Leeds, Leeds, LS2 9JT, England, UK; Tel: +44 (0) 11334 34323; Fax: +44 (0) 11334 34228; E-mail: d.j.beech@leeds.ac.uk
}

Methods for the rational design of isoform-specific agents have become increasingly popular. Antibodies in particular display high specificity for their target antigen. Already routinely used in a multitude of experimental procedures due to their versatility, antibodies can be engineered to recognise different proteins, including those expressed on the cell surface. While most biological applications use antibodies to detect the molecule of interest, some antibodies may have additional effects: For example, cross-linking to facilitate protein oligomerization, obscuring ligand-binding sites, or stabilizing a particular conformational state. For therapeutic uses, antibodies have been shown to selectively block the action of a molecule, target specific cells, and deliver other agents to target cells $[6,7]$.

In addition to having therapeutic potential, antibodies are attractive as biological tools. Custom-made antibodies have been recognised as specific ion channel blockers and have been used to demonstrate functions of channel proteins [8]. In many cases the antibodies target intracellular epitopes and so must be delivered by relatively difficult intracellular dialysis methods. However, extracellular epitopes have been successfully targeted, for example in ligand-gated ion channels including the P2X ATP receptors; these extracellular targeted antibodies increased the maximum current amplitude evoked by agonist application [9]. The modulation of other channel proteins has also been demonstrated, with antibody targeted to the extracellular Nterminus of plasma membrane STIM1 inhibiting arachidonic acid- and store-evoked $\mathrm{Ca}^{2+}$ entry $[10,11]$. A further example comes from studies of polycystin-2 (PC-2 or TRPP2), a $\mathrm{Ca}^{2+}$-permeable cation channel that plays a role in polycystic kidney disease. Fluid shear stress-evoked $\mathrm{Ca}^{2+}$ entry via PC-2 was abolished by polyclonal antibodies targeted to two distinct extracellular regions of the channel [12]. In contrast, antibody targeted to an intracellular region of PC-2 had no effect on the flow-induced $\mathrm{Ca}^{2+}$ response; evidence that an intracellular epitope is not accessible in live, intact cells without an intracellular delivery method. 
In the following sections we discuss progress with antibodies generated with the intention of producing extracellular-acting and selective inhibitors of six membrane-spanning segment ion channels (e.g. voltagegated $\mathrm{K}^{+}$channels, voltage-gated $\mathrm{Na}^{+}$channels, and TRP channels).

\section{E3 TARGETED ANTIBODIES: PRINCIPLES AND EXAMPLES}

Shaker $\mathrm{K}^{+}$channels, mammalian $\mathrm{K}_{\mathrm{V}} 1$ channels, and many related $\mathrm{Na}^{+}$and $\mathrm{Ca}^{2+}$ channels have a common theme of six membrane-spanning segments (S1-S6) per subunit, with intracellular amino- and carboxy-termini, and three connecting extracellular loops (E1-3). A simple yet important step has been the appreciation that targeting the E3 (or turret) region of six membrane-spanning ion channels is a constructive way forward for producing blocking agents [13, 14]. The E3 turret has been suggested to maintain the position of the ion selectivity filter but there is also evidence for it forming a direct interaction site for toxins and physiological modulators [15]. E3 may be suitable for targeting antibodies because it tends to be quite long, is rarely post-translationally modified, and is often accessible. The amino acid sequence of channel subtypes is often varied in this region, opening the possibility for isoform-specific interactions. Through E3-targeting there is the potential to produce isoform-specific agents that not only bind the channel but also disrupt channel function.

Eleven E3-targeted blocking antibodies have been reported, targeting nine different channels (Fig. 1). The first study used polyclonal antibodies targeted to the voltagegated $\mathrm{K}^{+}$channels $\mathrm{K}_{\mathrm{V}} 1.2$ and $\mathrm{K}_{\mathrm{V}} 3.1$ which inhibited whole cell currents and helped establish that $\mathrm{K}_{\mathrm{V}} 1.2$ is functional in neuronal cells [14]. Polyclonal antibodies also proved successful as inhibitors of the voltage gated sodium channel $\mathrm{Na}_{\mathrm{V}} 1.5[13,16]$, and of $\mathrm{N}-$ and P/Q-type voltage-gated $\mathrm{Ca}^{2+}$ channels [17]. NESOpAb is a polyclonal antibody designed to recognise the 'neonatal' splice variant form of $\mathrm{Na}_{\mathrm{V}} 1.5$, and is an efficient blocker of current conducted by the channel [16]. This study also highlights the remarkable ability of an antibody to differentiate between peptide regions in spliced variants that differ by just six amino acids. Furthermore NESOpAb has proved useful in studies of native channels, demonstrating an involvement of neonatal $\mathrm{Na}_{\mathrm{V}} 1.5$ in the enhancement of invasive behaviour of breast cancer cells, a result confirmed using RNA interference [18]. A further example is the D-III polyclonal antibody, which was developed as a blocker of P/Q-type voltage-gated $\mathrm{Ca}^{2+}$ channels in cerebellar granule cells [17]. D-III was used to demonstrate a direct link between voltage-gated $\mathrm{Ca}^{2+}$ channel antibodies and the pathogenesis of para-neoplastic cerebellar ataxia, suggesting that normal channel function and neurophysiology could be restored in patients by removal of damaging antibodies directed against these channels [17].

The E3-targeting method has also been applied to the Transient Receptor Potential (TRP) subfamily of ion channels, which show structural resemblance to the Shaker $\mathrm{K}^{+}$channel and are encoded by 28 genes in mammals [19]. TRP channels comprise a diverse family of non-selective cation channels, the functions and therapeutic value of which are only recently starting to emerge. A lack of specific pharmacological tools that discriminate between TRP subfamily members has increased the demand for E3targeted antibodies, which have been used to elucidate physiological roles for individual TRP channels.

T1E3 antibody, directed against E3 of TRPC1, initially revealed a role for TRPC1 as a contributor to $\mathrm{Ca}^{2+}$ entry in store-depleted vascular smooth muscle cells [11, 20, 21]. The results were validated using RNA interference and expression of dominant negative mutant TRPC subunit [11]. Additional studies showed TRPC1 up-regulation in proliferating vascular smooth muscle cells and functional importance in neointimal hyperplasia, events causing occlusive vascular disease [20]. T1E3 significantly reduced neointimal growth in cultured human vein segments, suggesting that a TRPC1 blocker could have potential in the prevention of vascular failure. Furthermore the contractile response of the vascular wall to endothelin-1 was inhibited by T1E3, suggesting a role for TRPC1 in this physiological response [22]. Functional significance of the channel was shown using T1E3 antibody to be up-regulated after organ culture [23]. In studies of fibroblast-like synoviocytes of the human rheumatoid arthritic joint T1E3 had a profound stimulatory effect on matrix metalloproteinase secretion, suggesting a role for constitutive activity of TRPC1 channels in suppressing release of remodeling factors [24]. The results were validated using RNA interference [24].

T1E3 directed against the same TRPC1 peptide was generated independently by another laboratory and used to reveal TRPC1 association and functional interaction with $\mathrm{Ca}^{2+}$-activated $\mathrm{K}^{+}$channels [25]. There is also a further antiTRPC1 antibody, targeted to a different sequence in E3 (Alomone Laboratories, Israel), which has been reported as an effective blocker of TRPC1-containing channels in human platelets [26]. In addition to TRPC1, E3-targeted antibodies have provided evidence for the physiological roles of further channels in the TRP superfamily.

E3-targeted anti-TRPC5 antibody, T5E3, demonstrated a functional role for TRPC5-containing channels in lanthanum or store-operated $\mathrm{Ca}^{2+}$ entry in pial arterioles, and in sphingosine-1-phosphate-evoked motility of vascular smooth muscle cells from the human saphenous vein $[13,27,28]$. The T5E3 antibody also potentiated matrix metalloproteinase secretion in fibroblast-like synoviocytes [24]. As with other related studies, the results were validated using RNA interference or expression of dominant negative mutant TRPC subunit [24, 27].

Polyclonal antibody directed against E3 of rat TRPV1 was effective at blocking channel activation by protons and heat, as well as chemical activation by the TRPV1 agonist anandamide and capsaicin [29]. Antibody inhibition was not reliant on the capsaicin binding pocket, as inhibition of channel activity was also achieved in a capsaicin insensitive mutant, suggesting that E3-targeted antibodies do not interact with agonist binding sites, particularly as the agonists tested act via independent mechanisms, and instead may obstruct the pore directly or stabilise a closed channel state.

Polyclonal antibody has been targeted to E3 of human TRPM3 [30], a poorly understood member of the $M$ 


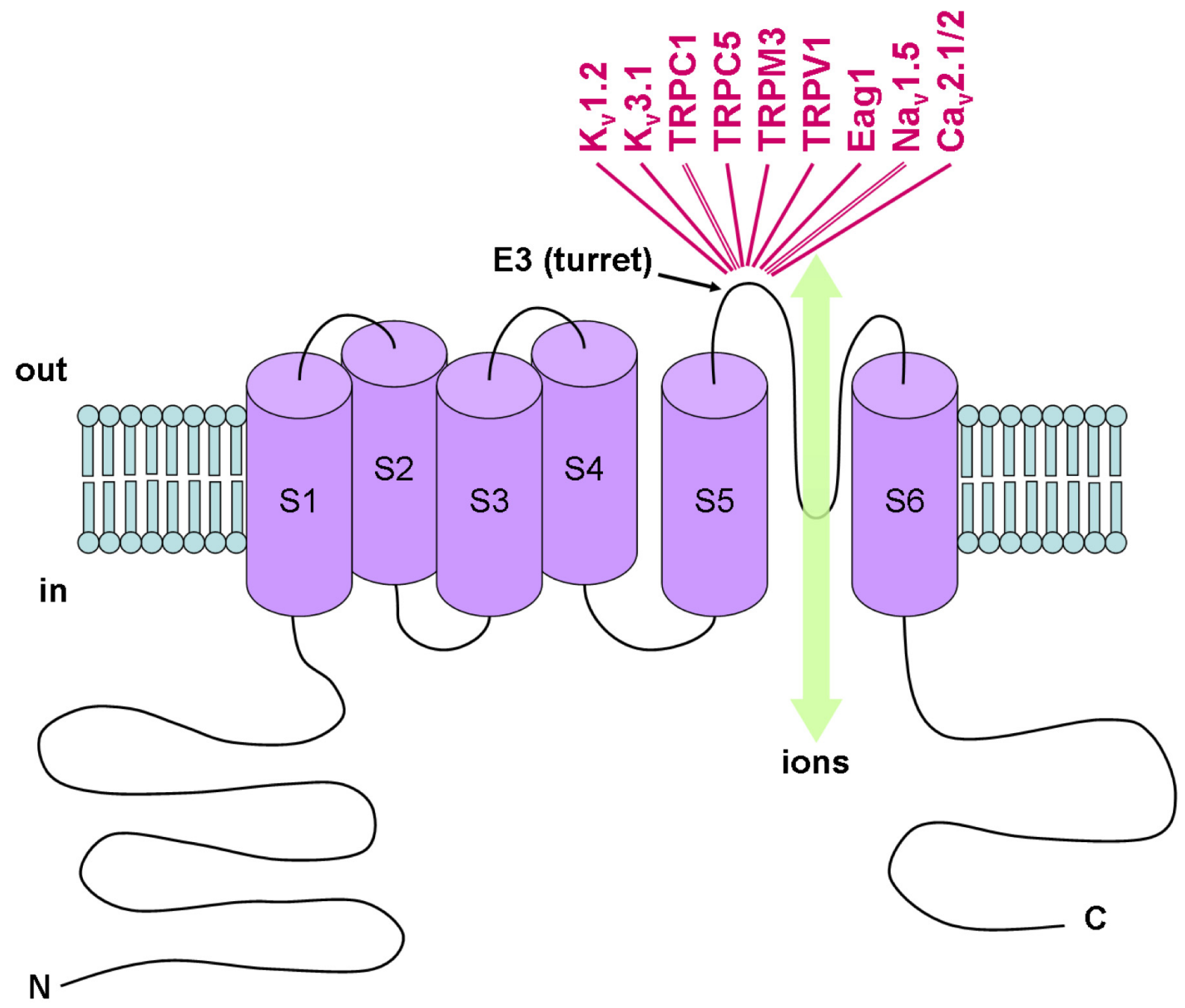

Fig. (1). Summary of successes with E3-targeted extracellular ion channel inhibitor antibodies. The schematic represents the predicted structure of a 6 transmembrane-spanning ion channel subunit. Note that $\mathrm{Na}_{\mathrm{v}} 1.5$ and $\mathrm{Ca}_{\mathrm{v}} 2.1 / 2.2$ are concatamers of 4 such subunits. E3 denotes the $3^{\text {rd }}$ extracellular loop. The double lines to TRPC1 and $\mathrm{Na}_{\mathrm{v}} 1.5$ represent multiple antibodies targeted to different peptide sequences in E3.

(melastatin) sub-type of TRP channel [31-33]. Overexpression studies show TRPM3 to form $\mathrm{Ca}^{2+}$-permeable non-selective cation channels regulated by factors including sphingosine and pregnenolone sulphate [31-34]. E3 antiTRPM3 antibody suppressed TRPM3-dependent signals evoked either by sphingosine or pregnenolone sulphate but lacked effects on TRPC5, TRPV4 or TRPM2 channels [30]. Potentially, the anti-TRPM3 antibody will be useful to determine functions of TRPM3 in native cells and tissues.

Therefore, E3-targeted antibodies are emerging as useful biological tools for the determination of physiological and pathological roles for ion channels. So far, these antibodies have given specific inhibition of their intended targets.

\section{PRACTICAL ASPECTS}

Only a relatively small number of channels have been targeted with extracellular antibodies but it is clear that the E3 approach has the capability to provide tools for determining the functions of ion channels. Experience with a wider range of ion channels will be important in determining the breadth of relevance of the approach and we hope more investigators will be tempted to try. Here we give practical guidance for investigators who might be considering the approach for their ion channel of interest. We give indications of the likely benefits and problems as well as recommendations on strategies for investigators without prior experience.

Addition of E3 antibody to the extracellular medium has been found to have acute blocking effect occurring over a time course of 10-15 minutes. Antibody can also be used in short pre-incubation protocols to minimize the amount of antibody dedicated to the experiment; in such experiments antibodies need not be retained in the extracellular medium during the recording of channel activity. Importantly antibodies are applied to living intact cells, reducing the chance for non-specific interactions because only extracellular regions of membrane proteins are exposed, rather than the entire proteome as in western blotting. It has been shown that the antibodies can be used on cells in culture as well as in experiments on excised whole tissues and in vivo. 
Intriguingly, in most cases E3 antibodies have produced only about half block of channel function, with a similar time course for inhibition in all cases. These findings suggest a common underlying mechanism of action. The mechanism is currently undetermined but possibilities include partial occlusion of the ion pore, allosteric modulation via E3 (the turret), and channel internalization. A common concern relating to the partial block is that it might not be sufficient to enable functional studies. However, functional studies have proved successful. Partial effects are also characteristic of the widely used RNA interference methodology, which often causes reduction rather than abolition of gene expression.

As with any methodology, experimental controls are important and use of multiple controls is advisable. Preimmune serum from the same donor animal is a commonly used control as it contains all components of the serum except those induced by the antigenic peptide. This control is most commonly available when the investigator has generated de novo antiserum. Other related controls include antiserum pre-mixed with the antigenic peptide, which prevents interaction of the antibody with target protein, and boiling the antibody which denatures protein (antibody) components but leaves other chemical factors intact. A different type of control is to determine if the effect of the antibody can be validated by independent methodology, such as RNA interference, expression of dominant negative mutant proteins, or specific gene disruption. Investigation of the functional specificity of the antibody is also worthwhile.

The most common starting point is to generate polyclonal antibodies to a specific peptide (Fig. 2). Such an approach has the advantage that it can generate high affinity antibodies within the polyclonal array and multiple antibodies to different regions of the same peptide. These aspects increase the chance of generating a blocking agent. However, the approach may also increase the chance of non-specific interactions. Non-specific interactions are most often troublesome if the titre of the antiserum is low. Therefore, chances of high quality desirable outcomes are greater if the titre of the initial antiserum is high. A common approach to decreasing non-specific interactions is to affinity-purify the antibodies. While purification may improve specificity it carries with it risk that high affinity components within the serum will be lost; and the high affinity components may be necessary for the functional effect. Another alternative is to purify all immunoglobulins from the serum (including the specific antibodies) using protein A agarose. In this case immunoglobulins from preimmune serum should be used as a nonspecific control. We have favoured using diluted antiserum as the starting point when determining if blocking antibodies might be present. In cases where non-specific effects arise because of non-antibody components of antiserum, prior dialysis in experimental buffer is advisable. If affinity-purified antibodies are used it should be noted that quite high antibody concentrations $\left(10-60 \mu \mathrm{g} \cdot \mathrm{ml}^{-1}\right)$ may be required to produce a blocking effect.

\section{GENERAL APPROACH FOR GENERATING E3- TARGETED ANTIBODY}

Many companies provide services for custom-made antisera and some investigators may prefer to take advantage of such services rather than generating antibodies in-house. The companies may offer important advice in light of their extensive experience. Most common is to use rabbit as a species to generate polyclonal antibodies; with this species a volume of at least $60 \mathrm{ml}$ of antiserum can be expected, which can be sufficient for a large number of experiments.

Fig. (2) outlines the complete process required for the custom design of a selective ion channel blocking antibody. Ion channels can vary greatly in amino acid sequence and function between species and so it is important to first decide on the channel and primary species of interest, and to obtain the cDNA clone. It is also equally important to ensure that there is an established functional assay for your chosen channel, as this will be necessary to confirm an antibody has a blocking effect.

Kyte-Dolittle or similar analysis can be used to map the hydrophobic and hydrophilic nature of amino acids within your channel sequence in order to ascertain surface exposed and membrane embedded regions of the protein [13]. This will allow for the determination of the location and sequence of the E3 region within the channel. Select a $\sim 20$-mer peptide sequence present in the E3 region, but take into account other available information regarding possible secondary structure and post-translational modification for this region that could impede antibody access. Also take note of the predicted antigenicity of the region, plus cross-species variations and splice variants. A sequence alignment of the E3 region with other related channels to determine sequence homology will reveal if your chosen peptide is unique to your channel and BLAST searches of public sequence databases will provide a broader perspective on other proteins that might contain the sequence.

For antibody generation, the addition of an N- or Cterminal cysteine to the chosen peptide sequence may be necessary to allow for conjugation to a support (e.g. KLH protein) and to aide affinity purification. It is, therefore, advisable (but not essential) to avoid a peptide sequence with an internal cysteine that might form a disulphide bridge with the terminal cysteine. Peptide synthesis should ideally provide 20-30 $\mathrm{mg}$ of peptide to enable a standard immunisation protocol (e.g. 2 rabbits in parallel) plus sufficient peptide for later control experiments and affinity purification. Prior to immunisation, collect preimmune sera from the host animal to serve as a useful control later on. Immunisation usually takes at least 4 weeks and you will be provided with test bleeds every week to monitor the immune response using an enzyme-linked immunosorbant assay (ELISA). The latter is an important first test for determining if antibodies have been generated and if there are general problems with antigen specificity. The ELISA also indicates the titre of antibody in different bleeds. If the titre is below 1:1000 (i.e. dilutions of $>1: 1000$ fail to bind the antigenic peptide), further immunisation boosts of the host rabbit may be helpful. Note that unless otherwise specified, final bleed serum will be unpurified (a mixture of immunoglobin isotypes) and will usually contain sodium azide preservative. In addition to the ELISA, further analysis of the antisera should be performed using western blotting. This will allow the comparison of over-expressed protein with endogenous levels to ensure the antibody binds the intended channel protein. 


\section{E3-targeted polyclonal antibody qeneration}

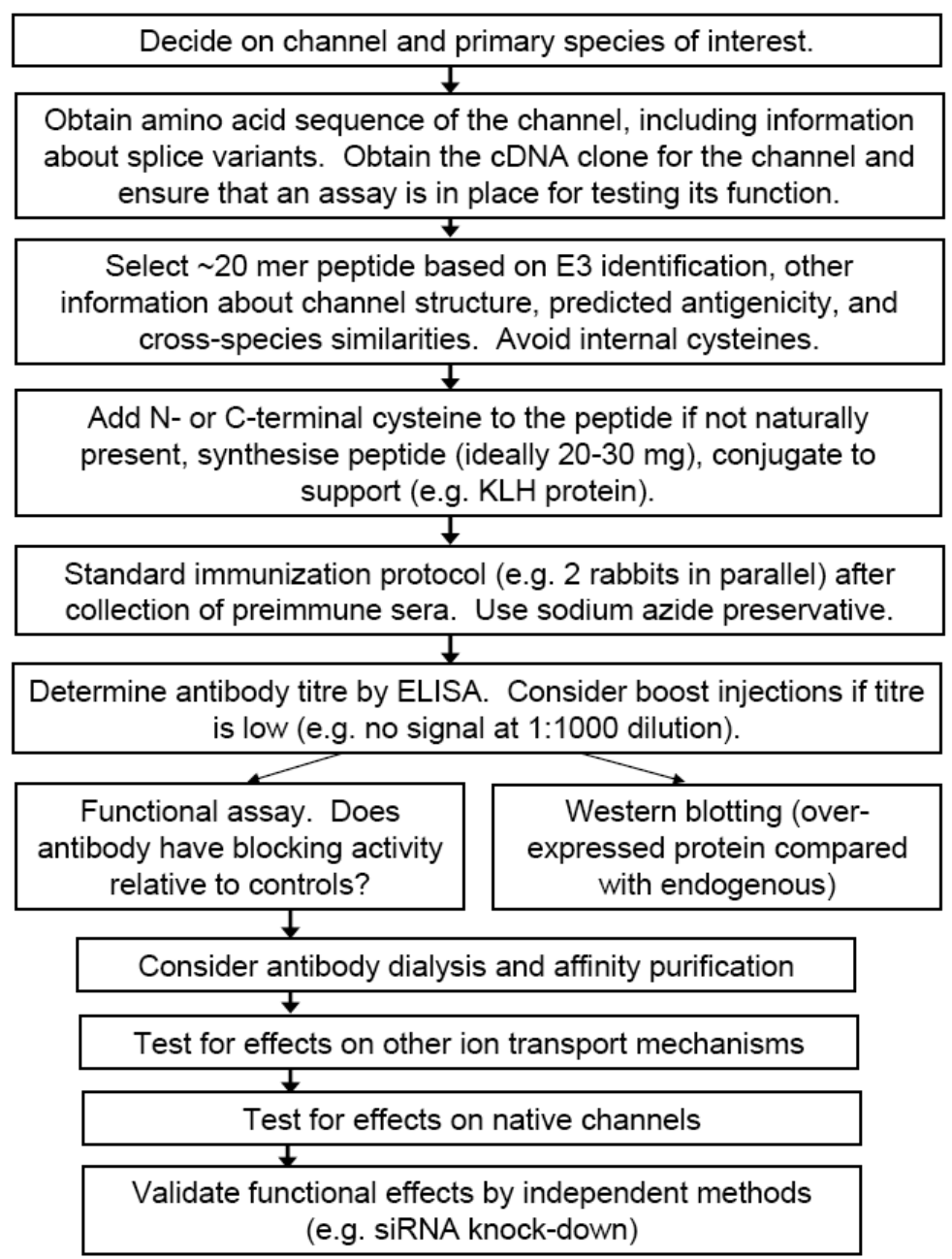

Fig. (2). Experimental approach for generating E3-targeted polyclonal antibodies. The flow chart chronicles key steps in the generation of an E3-targeted antibody. For full explanation see main text.

Once you are confident you have generated an antibody to your channel, you can perform functional assays. It is important to establish whether your antibody has blocking activity relative to controls such as preimmune antisera or peptide-adsorbed antibody. If preincubations with antibody are required or low dilutions are used, consider antibody dialysis to remove the sodium azide preservative. It is important to reassess the antibody titre following dialysis/purification using ELISA to ascertain if there has been unintentional loss of activity. Final bleed antisera will typically contain $5-10 \mathrm{mg} \cdot \mathrm{ml}^{-1}$ of IgG, of which $100 \mu \mathrm{g} \cdot \mathrm{ml}^{-1}$ will be specific antibody. Antibodies and/or serum should always be stored undiluted at $-80^{\circ} \mathrm{C}$ in working aliquots to prevent multiple freezing/thawing cycles.

If your antibody has blocking effect on your channel of interest, it is then advisable to test for off-target effects on other ion transport mechanisms and to validate any effects on cellular or tissue responses using independent methods (e.g. RNAi).

Lastly we wish to stress that potential users should understand that antibodies are protein reagents that carry with them special challenges, with need for appropriate controls and technical difficulties that are similar to those experienced with western blotting and immunocytochemistry. We recommend to investigators wishing to develop an inhibitor antibody that they establish a reproducible functional assay for the ion channel prior to antibody generation; in our experience, a robust 96-well plate assay is particularly helpful. We also emphasise the value of incorporating a validation method (e.g. RNAi) with initial functional tests to provide reassurance that any antibody effects arises from an action at the intended ion channel.

\section{MONOCLONAL ANTIBODIES}

Antisera containing polyclonal antibodies are useful in experimental situations but they are a finite supply and there is no guarantee that future efforts to generate similar antibody will be successful. Furthermore, while not without possibility, polyclonal antibodies are generally not considered for therapeutic purposes. Monoclonal antibodies can overcome such problems but identifying a functional monoclonal antibody against an ion channel may be a significant challenge. Unfortunately, monoclonal antibodies to E3 of TRPV1 lacked functional effect, even though 
polyclonal antibodies were effective [29]. The authors suggested that a mixed population of polyclonal antibodies might be necessary to achieve channel block. Nevertheless, monoclonal antibodies were produced that specifically inhibited the voltage-gated $\mathrm{K}^{+}$channel hEag1, implicating a function for the channel in tumour cell growth [35]. Monoclonal antibody to the ion channel auxiliary protein STIM1 has also been successful [11]. Therefore, it is possible to make monoclonal antibodies that inhibit ion channels but there are currently too few examples to be confident that it is a generally applicable approach. Mediumto-high throughput screening will probably be necessary in order to identify a high affinity monoclonal antibody that also inhibits ion channel function with specificity.

\section{CONCLUSIONS}

Understanding the functional relevance of ion channels is key to the development of therapeutic drugs. However the lack of selective channel blockers is a limiting factor in the discovery of channel functions under physiological and pathological conditions. Antibodies show remarkable specificity for their target antigens, and are powerful biological tools. Published evidence suggests that extracellular ion channel inhibitor antibodies can be generated and that E3-targeting is an appropriate strategy for certain types of ion channel. The antibodies have been suitable for studies of mechanisms and roles of ion channels in several different species and in cells, organs and the whole animal. However it is important to remember that such antibodies are not without limitations, and extensive characterisation and control experiments are necessary for any new E3 antibody. Careful handling is also essential, as for any protein reagent.

The early successes for E3-targeted antibodies raise interest in the approach for general usage. However, while further successes with polyclonal antibodies are expected, an important next step should occur with monoclonal antibodies, where considerable investment is needed if a therapeutic perspective is to materialise. The Tufts Center for the Study of Drug Development suggests that there are currently over 350 monoclonal antibodies undergoing clinical trials, and in 2006 the global market for these products exceeded $\$ 17$ billion. The number of therapeutic monoclonal antibodies entering clinical trials every year is rapidly increasing [36]. Crucial for making monoclonal antibodies that inhibit ion channels are methods that enable rapid identification of high affinity monoclonal antibodies with functional activity.

In summary, E3-targeting has proved thus far a successful method for the generation of isoform specific channel blocking agents. Here we review extracellular-acting antibodies generated as selective ion channel inhibitors and provide a general strategy for the generation and characterisation of an E3-targeted antibody.

\section{ACKNOWLEDGEMENTS}

The work in our laboratory is supported by the Wellcome Trust and the British Heart Foundation. We thank S Tumova for helpful comments on an early version of the manuscript.

\section{REFERENCES}

[1] Ackerman, M.J.; Clapham, D.E. Ion channels--basic science and clinical disease. N. Engl. J. Med., 1997, 336(22), 1575-1586.

[2] Ekberg, J.; Craik, D.J.; Adams, D.J. Conotoxin modulation of voltage-gated sodium channels. Int. J. Biochem. Cell Biol., 2008, 40(11), 2363-2368.

[3] Triggle, D.J. Drug targets in the voltage-gated calcium channel family: why some are and some are not. Assay Drug Dev. Technol., 2003, 1(5), 719-733.

[4] Dunlop, J.; Bowlby, M.; Peri, R.; Tawa, G.; LaRocque, J.; Soloveva, V.; Morin, J. Ion channel screening. Comb. Chem. High Throughput Screen, 2008, 11(7), 514-522.

[5] Dunlop, J.; Bowlby, M.; Peri, R.; Vasilyev, D.; Arias, R. Highthroughput electrophysiology: an emerging paradigm for ionchannel screening and physiology. Nat. Rev. Drug Discov., 2008, 7(4), 358-368.

[6] Brekke, O.H.; Sandlie, I. Therapeutic antibodies for human diseases at the dawn of the twenty-first century. Nat. Rev. Drug Discov., 2003, 2(1), 52-62.

[7] Schrama, D.; Reisfeld, R.A.; Becker, J.C. Antibody targeted drugs as cancer therapeutics. Nat. Rev. Drug Discov., 2006, 5(2), 147159.

[8] Dallas, M.; Deuchars, S.A.; Deuchars, J. Immunopharmacology-antibodies for specific modulation of proteins involved in neuronal function. J. Neurosci. Methods, 2005, 146(2), 133-148.

[9] Kim, M.; Spelta, V.; Sim, J.; North, R.A.; Surprenant, A. Differential assembly of rat purinergic P2X7 receptor in immune cells of the brain and periphery. J. Biol. Chem., 2001, 276(26), 23262-23267.

[10] Mignen, O.; Thompson, J.L.; Shuttleworth, T.J. STIM1 regulates $\mathrm{Ca} 2+$ entry via arachidonate-regulated $\mathrm{Ca} 2+$-selective(ARC) channels without store depletion or translocation to the plasma membrane. J. Physiol., 2007, 579(Pt 3), 703-715.

[11] Li, J.; Sukumar, P.; Milligan, C.J.; Kumar, B.; Ma, Z.Y.; Munsch, C.M.; Jiang, L.H.; Porter, K.E.; Beech, D.J. Interactions, functions, and independence of plasma membrane STIM1 and TRPC1 in vascular smooth muscle cells. Circ. Res., 2008, 103(8), e97-104.

[12] Nauli, S.M.; Alenghat, F.J.; Luo, Y.; Williams, E.; Vassilev, P.; Li, X.; Elia, A.E.; Lu, W.; Brown, E.M.; Quinn, S.J.; Ingber, D.E.; Zhou, J. Polycystins 1 and 2 mediate mechanosensation in the primary cilium of kidney cells. Nat. Genet., 2003, 33(2), 129-137.

[13] Xu, S.Z.; Zeng, F.; Lei, M.; Li, J.; Gao, B.; Xiong, C.; Sivaprasadarao, A.; Beech, D.J. Generation of functional ionchannel tools by E3 targeting. Nat. Biotechnol., 2005, 23(10), 1289-1293.

[14] Zhou, B.Y.; Ma, W.; Huang, X.Y. Specific antibodies to the external vestibule of voltage-gated potassium channels block current. J. Gen. Physiol., 1998, $111(4), 555-563$.

[15] Beech, D.J.; Sukumar, P. Channel regulation by extracellular redox protein. Channels(Austin), 2007, 1(6), 400-403.

[16] Chioni, A.M.; Fraser, S.P.; Pani, F.; Foran, P.; Wilkin, G.P.; Diss, J.K.; Djamgoz, M.B. A novel polyclonal antibody specific for the $\mathrm{Na}(\mathrm{v}) 1.5$ voltage-gated $\mathrm{Na}(+)$ channel 'neonatal' splice form. $J$. Neurosci. Methods, 2005, 147(2), 88-98.

[17] Liao, Y.J.; Safa, P.; Chen, Y.R.; Sobel, R.A.; Boyden, E.S.; Tsien, R.W. Anti-Ca2+ channel antibody attenuates $\mathrm{Ca} 2+$ currents and mimics cerebellar ataxia in vivo. Proc. Natl. Acad. Sci. USA, 2008, 105(7), 2705-2710.

[18] Brackenbury, W.J.; Chioni, A.M.; Diss, J.K.; Djamgoz, M.B. The neonatal splice variant of Nav1.5 potentiates in vitro invasive behaviour of MDA-MB-231 human breast cancer cells. Breast Cancer Res. Treat, 2007, 101(2), 149-160.

[19] Nilius, B.; Owsianik, G.; Voets, T.; Peters, J.A. Transient receptor potential cation channels in disease. Physiol. Rev., 2007, 87(1), $165-217$.

[20] Kumar, B.; Dreja, K.; Shah, S.S.; Cheong, A.; Xu, S.Z.; Sukumar, P.; Naylor, J.; Forte, A.; Cipollaro, M.; McHugh, D.; Kingston, P.A.; Heagerty, A.M.; Munsch, C.M.; Bergdahl, A.; HultgardhNilsson, A.; Gomez, M.F.; Porter, K.E.; Hellstrand, P.; Beech, D.J. Upregulated TRPC1 channel in vascular injury in vivo and its role in human neointimal hyperplasia. Circ. Res., 2006, 98(4), 557-563.

[21] Xu, S.Z.; Beech, D.J. TrpC1 is a membrane-spanning subunit of store-operated $\mathrm{Ca}(2+)$ channels in native vascular smooth muscle cells. Circ. Res., 2001, 88(1), 84-87. 
[22] Bergdahl, A.; Gomez, M.F.; Dreja, K.; Xu, S.Z.; Adner, M.; Beech, D.J.; Broman, J.; Hellstrand, P.; Sward, K. Cholesterol depletion impairs vascular reactivity to endothelin-1 by reducing storeoperated Ca2+ entry dependent on TRPC1. Circ. Res., 2003, 93(9), 839-847.

[23] Bergdahl, A.; Gomez, M.F.; Wihlborg, A.K.; Erlinge, D.; Eyjolfson, A.; Xu, S.Z.; Beech, D.J.; Dreja, K.; Hellstrand, P. Plasticity of TRPC expression in arterial smooth muscle: correlation with store-operated Ca2+ entry. Am. J. Physiol. Cell Physiol., 2005, 288(4), C872-880.

[24] Xu, S.Z.; Sukumar, P.; Zeng, F.; Li, J.; Jairaman, A.; English, A.; Naylor, J.; Ciurtin, C.; Majeed, Y.; Milligan, C.J.; Bahnasi, Y.M.; Al-Shawaf, E.; Porter, K.E.; Jiang, L.H.; Emery, P.; Sivaprasadarao, A.; Beech, D.J. TRPC channel activation by extracellular thioredoxin. Nature, 2008, 451(7174), 69-72.

[25] Kwan, H.Y.; Shen, B.; Ma, X.; Kwok, Y.C.; Huang, Y.; Man, Y.B.; $\mathrm{Yu}, \mathrm{S}$.; Yao, X. TRPC1 associates with $\mathrm{BK}(\mathrm{Ca})$ channel to form a signal complex in vascular smooth muscle cells. Circ. Res., 2009, 104(5), 670-678.

[26] Rosado, J.A.; Brownlow, S.L.; Sage, S.O. Endogenously Expressed Trp1 Is Involved in Store-mediated Ca2+ Entry by Conformational Coupling in Human Platelets. J. Biol. Chem. 2002, 277(44), 4215742163.

[27] Xu, S.Z.; Muraki, K.; Zeng, F.; Li, J.; Sukumar, P.; Shah, S.; Dedman, A.M.; Flemming, P.K.; McHugh, D.; Naylor, J.; Cheong, A.; Bateson, A.N.; Munsch, C.M.; Porter, K.E.; Beech, D.J. A sphingosine-1-phosphate-activated calcium channel controlling vascular smooth muscle cell motility. Circ. Res., 2006, 98(11), 1381-1389.

[28] Xu, S.Z.; Boulay, G.; Flemming, R.; Beech, D.J. E3-targeted antiTRPC5 antibody inhibits store-operated calcium entry in freshly isolated pial arterioles. Am. J. Physiol. Heart Circ. Physiol., 2006, 291(6), H2653-2659.
[29] Klionsky, L.; Tamir, R.; Holzinger, B.; Bi, X.; Talvenheimo, J.; Kim, H.; Martin, F.; Louis, J.C.; Treanor, J.J.; Gavva, N.R. A polyclonal antibody to the pre-pore loop of TRPV1 blocks channel activation. J. Pharmacol. Exp. Ther., 2006, 319(1), 192-198.

[30] Naylor, J.; Milligan, C.J.; Zeng, F.; Jones, C.; Beech, D.J. Production of a specific e xtracellular inhibitor of TRPM3 channels. Br. J. Pharmacol., 2008, 155(4), 567-573.

[31] Grimm, C.; Kraft, R.; Sauerbruch, S.; Schultz, G.; Harteneck, C. Molecular and functional characterization of the melastatin-related cation channel TRPM3. J. Biol. Chem., 2003, 278(24), 2149321501 .

[32] Lee, N.; Chen, J.; Sun, L.; Wu, S.; Gray, K.R.; Rich, A.; Huang, M.; Lin, J.H.; Feder, J.N.; Janovitz, E.B.; Levesque, P.C.; Blanar, M.A. Expression and characterization of human transient receptor potential melastatin 3(hTRPM3). J. Biol. Chem., 2003, 278(23), 20890-20897.

[33] Wagner, T.F.; Loch, S.; Lambert, S.; Straub, I.; Mannebach, S.; Mathar, I.; Dufer, M.; Lis, A.; Flockerzi, V.; Philipp, S.E.; Oberwinkler, J. Transient receptor potential M3 channels are ionotropic steroid receptors in pancreatic beta cells. Nat. Cell Biol., 2008, 10(12), 1421-1430.

[34] Grimm, C.; Kraft, R.; Schultz, G.; Harteneck, C. Activation of the melastatin-related cation channel TRPM3 [corrected] by D-erythrosphingosine. Mol. Pharmacol., 2005, 67(3), 798-805.

[35] Gomez-Varela, D.; Zwick-Wallasch, E.; Knotgen, H.; Sanchez, A Hettmann, T.; Ossipov, D.; Weseloh, R.; Contreras-Jurado, C.; Rothe, M.; Stuhmer, W.; Pardo, L.A. Monoclonal antibody blockade of the human Eag1 potassium channel function exerts antitumor activity. Cancer Res., 2007, 67(15), 7343-7349.

[36] Reichert, J.M.; Rosensweig, C.J.; Faden, L.B.; Dewitz, M.C. Monoclonal antibody successes in the clinic. Nat. Biotechnol., 2005, 23 (9), 1073-1078

(C) Naylor and Beech; Licensee Bentham Open.

This is an open access article licensed under the terms of the Creative Commons Attribution Non-Commercial License (http://creativecommons.org/licenses/by$\mathrm{nc} / 3.0 /$ ) which permits unrestricted, non-commercial use, distribution and reproduction in any medium, provided the work is properly cited. 